\title{
The Stock Market between Classical and Behavioral Hypotheses: An Empirical Investigation of the Warsaw Stock Exchange
}

\author{
Mostafa Raeisi Sarkandiz**, Robabeh Bahlouli* \\ *Department of Management and Economics, University of Tabriz, Iran
}

Submitted: April 11, $2019 \bullet$ Accepted: August 5, 2019

\begin{abstract}
In empirical studies of the efficient market hypothesis using a classic approach, attention has generally been paid to the weak form of performance; other aspects of efficiency, such as informational efficiency, have not been addressed. Also, the study of alternative theories, such as behavioral hypotheses, is neglected. This article seeks to investigate not only the weak and informational forms of the efficient market hypothesis, but also to test the adaptive and fractal market hypotheses as two alternative theories by conducting an empirical study on the Warsaw Stock Exchange.
\end{abstract}

JEL classification: C12, G14

Keywords: efficient market hypothesis, informational efficiency, adaptive market hypothesis, fractal market hypothesis, Warsaw Stock Exchange

\section{Introduction}

Since Fama (1965) first introduced the concept of market efficiency, a considerable amount of economic investigation has been centered on whether to accept this hypothesis. Numerous definitions of market efficiency all emphasize a common notion that if the market is

\footnotetext{
${ }^{*}$ Corresponding Author. Address: Department of Management and Economics, University of Tabriz, 29 Bahman Boulevard 51666, Tabriz, Iran. Email: mostafa.raeisi.sarkandiz@gmail.com
} 
efficient, asset prices will reflect existing information (Eakins and Mishkin, 2012). In other words, prices reflect the fundamental information about active companies in the market. This hypothesis therefore states that any price deviations are quickly corrected by arbitrageurs. Nonetheless, Shleifer (2000) asserts, in contrast to the efficient market hypothesis, that the behavioral finance theory indicates arbitrage is risky and therefore limited. The importance of establishing which of these two hypotheses is correct is that if the market is not efficient it can be argued that with limits on arbitrage, there is the possibility of creating asset bubbles. Therefore, prices have not followed their fundamental trend. With the continuation of deviations from the fundamental trend and an incremental increase of the bubble, there will probably be an economic crash.

After several periods of high price fluctuations in stock exchanges, the efficient market hypothesis was seriously questioned and Keynes' (1936) idea, which suggested the possibility of creating an asset price bubble, was again considered. Shiller (1979) introduced the variance bounds tests to investigate the existence of bubbles in the market and the possibility that the market hypothesis was rejected. In the following years, Diba and Grossman (1988) examined a cointegration relationship between the prices and dividends of stocks in line with the market efficiency hypothesis and the existence of a bubble when this hypothesis was violated. Subsequently, Evans (1991) introduced a different type of a bubble called "periodically collapsing bubble" and the cointegration method did not allow for the diagnosis of this bubble. Finally, Phillips et al. (2011) introduced the SADF test and Phillips et al. (2015) introduced the GSADF test, making it possible to detect more probable bubbles. In reviewing the numerous empirical studies that challenged the efficient market hypothesis, Peters (1994) introduced the fractal market hypothesis as an alternative which could better explain market characteristics. This hypothesis, unlike the efficient market hypothesis, declares that market agents respond to new information with delays and therefore prices follow a long memory process.

In 2004, Lo proposed the adaptive market hypothesis, which states that market performance has a dynamic trend: in some periods the market is efficient, but in other periods the market is inefficient. In other words, even if the market is not functioning efficiently in a given time period, it is likely that it behaves efficiently in some of its sub-intervals. The logic behind this hypothesis is based on the principles of behavioral economics, which argue that, in many cases, the behaviors of market agents are biased and people generally make their decisions based on past results. Hence, market efficiency can vary according to market conditions (Soteriou and Svensson, 2017). This hypothesis assumes that the behavior of market agents will be different during ascending and descending trends, and although this will not allow the market to be efficient for a long period, in some sub-periods the market will behave efficiently. Lo (2012) also states that the efficient market hypothesis is not an 
incorrect hypothesis, but is merely an incomplete model.

It is worth noting that examining the existence of a bubble in a market can be considered an indirect method of evaluating the efficient market hypothesis because, in the presence of a bubble, it is obvious that this hypothesis is violated. This paper focuses on direct methods of assessing the efficient market hypothesis. Furthermore, to obtain a more complete picture of markets and the behavior of their agents, the adaptive and fractal market hypotheses will also be tested.

The primary goal of this study is to achieve an appropriate hypothesis to explain the behavior of prices and active agents in the Warsaw Stock Exchange. Describing the behavior of the market with a coherent hypothesis can help with the analysis and prediction of market trends, and allow decision makers to apply their monetary policy with less uncertainty.

The structure of the paper is as follows. The data and descriptive statistics are introduced and presented in Section 1. In Section 2, the efficient, adaptive, and fractal market hypotheses are studied using econometric methods. In addition, some of the methods used in the empirical studies carried out in this area are critiqued. Finally, in Section 3, concluding remarks and suggestions for future research are presented.

\section{Data}

The data used in this research are the daily closing prices of the WIG20 index of the Warsaw Stock Exchange from January 2010 to May 2018. The WIG20 indicator is a weighted index of the 20 largest active companies in the Warsaw Stock Exchange. The statistical software packages JMulti, Eviews9, and Excel 2013 are used for the analyses.

Econometric methods require that the time series of returns be used instead of the time series of prices. In this regard, the logarithmic difference of prices has been used to calculate the time series of returns:

$$
r_{t}=\log \left(p_{t}\right)-\log \left(p_{t-1}\right) .
$$

The trends of prices and returns are shown in Figures 1 and 2, respectively. The descriptive statistics for the returns are reported in Table 1.

The trend in the returns shows some fluctuations in the market, and the skewness of the data clearly indicates a deviation from the normal distribution. The Jarque and Bera (1980) normality test (J-B) also reveals that the distribution of the data does not follow a normal pattern, so at first glance, it seems that the market may be showing some sort of inefficient behavior.

The period under review, which is illustrated in Figure 1, relates to the post-2008 global economic crisis. An important point to be drawn from the chart is that, until 2016, the 
overall trend in prices is of decline and fluctuation; after 2016, which coincided with the depreciation of the world markets from the recession, we again see growth in prices. It seems that the Warsaw Stock Exchange, like many capital markets in the European Union, has a significant correlation with global economic fluctuations, which could be a reason for the development of Poland's economic incoherence in relation to the global economy. It should be noted that this is a hypothesis based on an empirical observation, thus to be confirmed or rejected through analysis, which is beyond the scope of this article.

\section{Methodology and Discussion}

In the first part of this section, we examine the weak form of the efficient market hypothesis using two methods: unit root tests and Shannon's entropy method. In the second part, we study the adaptive market hypothesis using the variance ratio test. In the third part, we examine the fractal market hypothesis using the Hurst index. We also been attempt to analyze common technical mistakes related to some empirical studies carried out in these areas.

\subsection{Efficient Market Hypothesis}

In this part, the efficient market hypothesis is tested based on unit root tests and Shannon's entropy method.

\subsubsection{Unit Root Tests}

From the econometric point of view, the weak form of the efficient market hypothesis means that prices follow a random walk process, making it impossible to forecast prices. Several empirical studies have been performed to establish whether this condition holds true in stock markets, including Dedunu (2017) in the Sri Lankan stock exchange, Ananzeh (2016) in Amman Jordan, Shaker (2013) in Finland and Sweden, Borges (2010) in the stock exchanges of several European countries, Dragota et al. (2009) in Bucharest, and Nagayasu (2003) in the Japanese stock exchange. The analysis process in these studies was based on unit root detection tests founded on the daily prices of stock indices.

Two technical flaws can be identified in these analyses. First, the existence of structural breaks in the markets were not examined in any of these studies. Perron (1989) indicated that the presence of a structural break in data with an increase in type 1 errors would lead to a reduction in the strength of diagnostic tests. This means that even if the null hypothesis is correct, the tendency to reject it increases. The second issue goes back to the tests employed: most studies have used the Dickey and Fuller (1981) test (ADF) along with the Phillips and 
Perron (1988) test (P-P) and the variance ratio test presented in Lo and Mackinley (1988). In the case of the ADF test, when the autocorrelation of data is negative, taking advantage of the AIC and BIC criteria to determine test lag length can be deceptive and these criteria will select a shorter lag (Ng and Perron, 2001). In addition, the ADF and P-P tests use the same critical values table, both of them suffer from low diagnostic power, and they are often recognized as biased tests (Cochrane, 1991).

Unfortunately, in some instances, the Wald and Wolfowitz (1940) nonparametric testknown as the Runs test-was employed to conclude whether unit roots were present. But the rejection of the null hypothesis with the Runs test does not necessarily imply market inefficiency; the rejection may have other causes, such as the ARCH effect or structural changes in the time series.

The final point relates to the unit root tests used in the research cited above. Although these tests have a nonstationary null hypothesis, the alternative hypothesis does not state the static behavior of the time series. In order to obtain a precise characterization of the time series, in the absence of the unit root, the behavior of the time series must be specified. If the differential parameter is in the interval $(0.5,1)$, then the time series asymptotically has a unit root and will behave like a random walk process. If the differential parameter is in the interval $(-0.5 ; 0.5)$, then the series has a long memory and its behavior will be stable through time (Shao and $\mathrm{Wu}, 2007$ ). Thus, in addition to the unit root tests, it is also necessary to use the Kwiatkowski et al. (1992) test (KPSS). Unlike for the other tests, the null hypothesis of the KPSS test is stationary. If, after the rejection of the null hypothesis of other unit root tests, the null of the KPSS test is rejected, then it must be inferred that the differential parameter is a non-integer number and, thus, it will be necessary to estimate its value through existing methods. Therefore, to avoid the above-mentioned problems in this procedure, the probability of structural breaks has been investigated before undertaking any further analysis. For more accurate inferences, along with the common unit root tests, some other tests have also been used, which we will further discuss.

Before any analysis, the Runs test is performed on the data. In this test, the actual number of runs is being compared with the expected number of runs. So, we have:

$$
\begin{gathered}
\bar{R}=\left(\frac{2 n_{1} n_{2}}{n_{1}+n_{2}}\right)+1 \\
S^{2}=\frac{2 n_{1} n_{2}\left(2 n_{1} n_{2}-n_{1}-n_{2}\right)}{\left(n_{1}+n_{2}\right)^{2}\left(n_{1}+n_{2}-1\right)}+1
\end{gathered}
$$

where $\bar{R}$ denotes the expected number of runs, $S^{2}$ denotes the standard error of the expected number of runs, and $n_{1}$ and $n_{2}$ are the sums of the positive and negative runs, respectively. The test statistic is calculated as follows: 


$$
Z=\frac{R-\bar{R}}{S}
$$

where $R$ denotes the actual number of runs. The critical value for the test is based on the standard-normal $Z$ table. The null hypothesis indicates that the time series is randomly distributed. The results of this test are reported in Table 2.

As the results show, at a significance level of $5 \%$, the null hypothesis of this test is not rejected. In other words, from the perspective of this test, the market is efficient.

To identify the potential structural breakpoints in the data, the Bai and Perron (1998, 2003) test has been employed. The motivation for using this test is that, unlike traditional tests such as proposed by Chow (1960), it does not require prior information about probable breakpoints. Additionally, this test calculates the exact time of breakpoints. The results of this test are shown in Table 3.

As can be deduced from Table 3, the time series has no breakpoints. These results imply that significant structural changes in the performance and regulations of the Warsaw Stock Exchange have not been made, and that external shocks from macroeconomic adjustments in Poland have also not affected the market. Therefore, without any concern about misspecification, we can use unit root tests. To investigate the existence of a unit root, along with the traditional ADF and P-P tests, the Elliott et al. (1996) test (known as the DF-GLS) has likewise been employed because in statistical simulations, the DF-GLS test has greater power than the ADF test ( $\mathrm{Wu}, 2010)$. The multiple variance ratio test proposed by Chow and Denning (1993), which is robust to heteroscedasticity, has also been used. Likewise, we use the KPSS test to detect the time series features. The results of these tests at a $5 \%$ significance level are shown in Tables 4 and 5 .

The results of the unit root and variance ratio tests clearly indicate that the time series returns do not follow a random walk process and, therefore, the efficient market hypothesis does not apply throughout the study period. This means that prices have a predictable trend, and it is feasible for shareholders to gain unusual profits (over market performance) by using available information because stock price variations are not random.

\subsubsection{Shannon's Entropy}

The concept of informational efficiency declares that prices contain information from companies active in the market, and changes in information flow will change trends in prices. In other words, new information will quickly affect the behavior of market actors and cause price changes. However, the key point is that the market agents with access to prices can access all the information. Beaver (1981), in a descriptive definition, states that the market would be efficient with respect to a set of information if disclosure of this information to all 
market players did not lead to a change in equilibrium prices.

In this section, we will discuss the Warsaw Stock Exchange in terms of informational efficiency. It should be noted that in the previous section, the weak performance of the market was examined and this hypothesis was not confirmed. In this study, to measure the informational efficiency of the stock market, Shannon's (1948) entropy equation is used.

In the first step, we use the following function to transform the returns series into a binary series:

$$
S_{t}= \begin{cases}0 & r_{t}<0 \\ 1 & r_{t} \geq 0\end{cases}
$$

where $r_{t}$ denotes the returns series. We consider the ratio of the number of zeros to the whole numbers equal to $P$. It is obvious that this ratio will be equal to $1-P$ for the ones. Therefore, based on the method presented in Risso (2008), we will have:

$$
H_{s}=-\left\{P \cdot \log _{2} P+(1-P) \cdot \log _{2}(1-P)\right\}
$$

where $H_{s}$ denotes Shannon's entropy index. $H_{s}$ is a value in the interval $[0,1]$ and the maximum value is obtained when $P=\frac{1}{2}$. In the latter case, when the maximum value is obtained, we say that the market is efficient. Therefore, for values less than one, the market will not be efficient.

In order to obtain stable values, the rolling-recursive window method, with two initial windows containing 50 and 100 data elements, has been used to calculate the desired index. In this paper, contrary to the approach outlined in Phillips et al. (2011) in the selection of steps for the rolling-recursive window method, each of which adds new data to the previous dataset, the steps add 50 or 100 data elements. The reason for this is that Phillips et al. (2011) used monthly data, and within a month (as much as the length of a step), it is possible to change the behavior of the market somewhat. In this study we use daily data, and a oneday increase to the previous dataset will not lead to a significant change in the data process, whereas these changes can be significant over 50 or 100 days of trading. So, steps of 50 and 100 data points, a 50-window and 100-window, respectively, have been selected for use in this research.

The descriptive statistics of the $H_{s}$ values are given in Table 6 . The mean of the values is used as the desired index. The values obtained are close to 1 , so we need to test their equality with 1 . The one-way t-test is used for this purpose. It is clear that in the case of the 100-window, the distribution of data is normal, but this is not true for the 50-window.

A one-way t-test for examining the mean of a sample requires the normal assumption because this test is highly sensitive to large skewness and heavy-tailed distributions (Cressie and Whitford, 1986). Unfortunately, in many applications of this test, the assumption of 
normality is not taken into account and, therefore, the statistical inference is generally inaccurate. To solve this problem, we use the Hall (1992) method, which is known as the trimmed $t$-statistic. The statistics used in this method are calculated as follows:

$$
H_{t_{w}}=\left\{\left(\overline{X_{t}}-\mu_{t}\right)+\frac{\widehat{\mu_{w}}}{\left(6 f{\widehat{\mu_{w}}}^{2}\right)}+\widehat{\mu_{w}} \frac{\left(\overline{X_{t}}-\mu_{t}\right)^{2}}{3{\widehat{\sigma_{w}}}^{4}}+\frac{{\widehat{\mu_{w}}}^{2}\left(\overline{X_{t}}-\mu_{t}\right)^{3}}{27{\widehat{\sigma_{w}}}^{8}}\right\} /\left(\frac{\widehat{\sigma_{w}}}{\sqrt{f}}\right)
$$

If $n$ is equal to the sample size and $e=[\beta n], 0 \leq \beta<0.5$ and $2 e$ is the trimmed value from the ordered data, then $f=n-2 e$ will be the effective sample size. So, we have:

$$
\begin{aligned}
& \overline{X_{t}}=\frac{1}{f} \sum_{i=e+1}^{n-e} X_{i} \quad \text { Sample Trimmed Mean } \\
& Z_{i}=\left\{\begin{array}{lr}
X_{e+1} & X_{i} \leq X_{e+1} \\
X_{i} & X_{e+1}<X_{i}<X_{n-e} \\
X_{n-e} & X_{i} \geq X_{n-e}
\end{array}\right. \\
& \overline{X_{w}}=\frac{1}{n} \sum_{i=1}^{n} Z_{i} \quad \text { Sample Winsorized Mean }
\end{aligned}
$$

Therefore, we can write:

$$
\begin{gathered}
{\widehat{\sigma_{w}}}^{2}=\sum_{i=1}^{n} \frac{\left(Z_{i}-\overline{X_{w}}\right)^{2}}{f-1} \quad \text { Squared Standard Error of Sample Trimmed Mean } \\
\widehat{\mu_{w}}=f \sum_{i=1}^{n} \frac{\left(Z_{i}-\overline{X_{w}}\right)^{3}}{(f-1)(f-2)} \quad \text { Unbiased Trimmed Third Central Moment }
\end{gathered}
$$

Also, $\mu_{t}$ is the default value under the null hypothesis. The critical value of this statistic is calculated according to the standard table of the Student's $t$-distribution.

Therefore, for the 100-window, we use the standard $t$-test, but for the 50-window, we employ the trimmed $t$-test. The trimming factor is $10 \%$ because after trimming the distribution of the data follows the normal distribution (the J-B probability for the trimmed sample is 0.915). The null hypothesis is $H_{0}: \mu=1$ and the alternative is $H_{1}: \mu<1$. The test results are reported in Table 7.

The $t$-test results indicate that the null hypothesis is rejected for both windows. That is, the index value will be less than 1 , and therefore the informational efficiency hypothesis is also rejected.

The rejection of the informational efficiency hypothesis implies that new information 
in the market is not immediately reflected in the prices. This could be due to a lack of access to corporate information. Informational inefficiency can likewise be due to a lack of professionalism among traders such that they do not respond quickly to new information. If the efficient market hypothesis was rejected, it could be possible to acquire excess returns in the Warsaw Stock Exchange.

It is worth noting that the results of the Runs test indicate market efficiency, but the other two methods have rejected this hypothesis. Hence, as mentioned at the beginning of this section, the Runs test cannot be a good benchmark for examining the efficient market hypothesis.

\subsection{Fractal Market Hypothesis}

The failure to validate the efficient market hypothesis leads us to analyze an alternative hypothesis to explain the behavior of prices in the stock market. In this regard, the fractal market hypothesis is tested as a model based on the principles of behavioral economics. This hypothesis states that the returns follow a long memory process. For this purpose, the Hurst index is used to examine market behavior. This index is a numerical value that is in the range of $(0,1)$. If $H=0.5$, then the series has a random walk behavior. If $0.5<H<1$, then the time series has a positive correlation and will display long memory behavior. Finally, if $0<H<0.5$, then the time series has a negative correlation and will show mean-reverting behavior (Peters, 1994).

Several studies have been conducted on market behavior using the Hurst index (for example, Van Quang, 2005; Panas and Ninni, 2010; Morales et al., 2012; Oprean et al., 2017), but some of these studies have flaws. First, due to the possible structural breaks in the data and the lack of stability of the trends, the Hurst index must be estimated using the rolling-recursive window method, but in some studies the calculation of the parameter was made once and over the entire time period. Second, despite the use of the rolling-recursive window method, in some cases the analysis is presented based on the calculated value, but because this index is an estimate, it requires a statistical inference. In other words, this value should be subjected to statistical testing. Finally, in some studies, only one window has been used, but in order to ensure the results achieved, it is advisable to use at least two different windows. Therefore, in this study, for calculating Hurst index values, similar to the calculation of Shannon's entropy, the rolling-recursive window method was used based on two different windows with steps of 50 and 100, and the optimum amount was ultimately tested.

The method used to estimate the Hurst index is the (R/S). Again, similar to the calculation of Shannon's entropy, this method also requires that the time series of returns be used instead of using the time series of prices. It is also necessary that the return series have no unit roots. According to the unit root test results in Subsection 2.1.1, this condition is 
clearly established and, therefore, the Hurst index can be employed.

The index, first introduced by Hurst (1951), is estimated as follows:

$$
H=\log (R / S) / \log (T)
$$

Here, the presentation of the calculation method (R / S) has been avoided and we refer the reader to Resta (2012).

The descriptive statistics of the obtained Hurst values are given in Table 8. The mean of the values is used as the parameter and, therefore, its meaningful test is based on the t-test.

As can be seen, in both of the above categories, the data distribution has a nonparametric positive skewness, which means that the mean is greater than the median. Also, the calculated skewness is clearly greater than the skewness of the normal distribution. In addition, at a $5 \%$ significance level, the null hypothesis of the J-B test was rejected, so the distribution of the calculated Hurst values is abnormal. So, again, we must use trimmed $t$-statistics. The trimming of the sample by $10 \%$, by adjusting the skewness and kurtosis of the data, led to their normal distribution and, therefore, the statistical inference based on the trimmed $t$-statistic would be efficient. The results of the J-B test for the trimmed sample are reported in Table 9.

The tests of the Hurst values for the 50-window and 100-window with the null hypothesis $H_{0}: \mu=0.5$ against the alternative $H_{1}: \mu<0.5$ are considered. The test results are described in Table 10. Clearly, for both of the windows, the null hypothesis is rejected. Therefore, the efficient market hypothesis is also rejected. The important point is that if the standard $t$-statistic was used, the null hypothesis for the 100-window would not be rejected. Also, the calculated parameter is in the range of $(0,0.5)$ and so the behavior of the series is not long memory. Likewise, $0<H<0.5$ indicates that any increase in any of the series terms will entail its decrease at the next moment in time. Therefore, the fractal market hypothesis is also rejected during the entire period.

\subsection{Adaptive Market Hypothesis}

As noted above, the adaptive market hypothesis states that in some of the sub-periods, market efficiency may be possible. The volume of empirical studies carried out in this area is not comparable to those of the efficient market hypothesis, but some of the most important studies in this field are: Todea et al. (2009), Neely et al. (2009), Kim et al. (2011), Charles et al. (2012), Hiremath and Narayan (2016), Gyamfi (2018). The methods used in these studies emphasize the autocorrelation tests, both linear and non-linear. The results of most research in this field have confirmed the validity of the adaptive market hypothesis, but the main point in all this research is that there is no proper mechanism for determining the 
sub-intervals, and the method used is generally based on the rolling-recursive window. It is worth noting, however, that the present study does not propose a specific method. Also, in order to study the adaptive market hypothesis, in this study the multiple variance ratio test was used. Because the market did not work efficiently throughout the entire study period, finding at least one sub-period in which market behavior was efficient would be sufficient to confirm the adaptive market hypothesis.

In determining the sub-intervals, not only has the rolling-recursive window method been used with 50-step data, but also, to separate the intervals that have more fluctuations than others, the entire period is divided into several sub-intervals with data volumes of 100, 150, $300,350,700$, and 1,050. The results of the analyses of these 95 intervals are reported in Tables 11 and 12 .

As can be clearly derived from the results, among all the subperiods studied the market behaved efficiently only between January 2, 2014, and May 27, 2014. Therefore, it can be stated that throughout the study period, the adaptive market hypothesis has been validated in the Warsaw Stock Exchange. This indicates that individual trading strategies change over time and do not occur according to a fixed and specific pattern. Further, market agents are comprised of both beginners and experts, and cannot be classified as a homogenous collection (as assumed in the efficient market hypothesis). Accordingly, the behavioral economics approach is substantially better than traditional approaches for interpreting the behavior of the stock market and its agents.

\section{Concluding Remarks}

This study examines the existing assumptions about the behavior of prices in the Warsaw Stock Exchange. Before undertaking the analysis, the presence of structural changes was investigated using the structural breaks test. The results confirmed there were no structural breaks in this data. In order to investigate the efficient market hypothesis, four different unit root tests-ADF, P-P, DF-GLS, and KPSS - were used, along with the variance ratio test. The results of these tests showed that the market is not efficient at a $5 \%$ significance level. For a more detailed analysis, Shannon's entropy index was evaluated using a rollingrecursive window method to investigate market informational efficiency; the results of this test confirmed the market inefficiency. To obtain a better understanding of market performance, the fractal market hypothesis was tested as an alternative to the efficient market hypothesis. To this end, the Hurst index calculated with a rolling-recursive window method was used. The results show that at some intervals prices followed a long memory process, but in most of the intervals they followed a mean reverting process. However, throughout the period under review, the desired time series followed a mean reverting process and so the fractal market 
hypothesis was rejected. In contrast to the efficient market hypothesis, the adaptive market hypothesis states that although a market can be inefficient throughout the entire period, there will be intervals in which market behavior is efficient. To test this hypothesis, the multiple variance ratio test was performed using the rolling-recursive window method. Additionally, in order to study the time series more precisely, the entire time period was divided into sub-intervals where the fluctuations of returns are different. The results of the analysis of the 95 study periods showed that in just one of these intervals, the market was efficient. As there exists at least one sub-period in which the market was efficient, the adaptive market hypothesis was confirmed.

In general, it can be stated that during the period under consideration, it was possible most of the time to earn returns greater than the market yield on the Warsaw Stock Exchange. Also, the market trend in most of the sub-periods was mean-reverting and so there was a downtrend following an uptrend in prices, and vice versa. In the sub-periods where the long memory process was followed, an uptrend was followed by another uptrend and, similarly, a downtrend was succeeded by another downtrend.

It should be noted that, in testing the adaptive market hypothesis, the results are sensitive to the choice of sub-intervals and, therefore, the results of this research are limited to the selected intervals. Consequently, this study does not rule out the possibility of more subperiods in which the hypothesis may be validated. Therefore, in order to carry out future research, it will be helpful to use an effective method for determining the maximum possible number of sub-intervals.

Ultimately, it is worth noting that in this paper, conventional econometric techniques are employed to examine the hypotheses. However, the authors are considering two approaches to future investigations of the Warsaw Stock Exchange. The first approach is based on the use of chaos theory to study the nonlinear, dynamic, and chaotic nature of stock prices. In the second approach, due to the lack of evidence to support an efficient market hypothesis and therefore, the possibility of price bubbles forming in the market, the diagnosis and detection of such bubbles applying the latest tools, such as the SADF, GSADF, and BSADF tests, will be addressed.

\section{Funding Sources}

This research did not receive any specific grants from funding agencies in the public, commercial, or not-for-profit sectors. 


\section{References}

Ananzeh, I. (2016). Weak Form Efficiency of the Amman Stock Exchange: An Empirical Analysis (2000-2013). International Journal of Business and Management, 11(1):173-180.

Bai, J. and Perron, P. (1998). Estimation and Testing Linear Models with Multiple Structural Changes. Econometrica, 66(1):47-78.

Bai, J. and Perron, P. (2003). Computation and Analysis of Multiple Structural Change Models. Journal of Applied Econometrics, 18(1):1-22.

Beaver, W. H. (1981). Market Efficiency. Accounting Review, 56(1):23-27.

Borges, M. R. (2010). Efficiency Market Hypothesis in European Stock Markets. The European Journal of Finance, 16(7):711-726.

Charles, A., Darne, O., and Kim, J. H. (2012). Exchange Rate Return Predictability and the Adaptive Market Hypothesis: Evidence from Major Foreign Exchange Rate. Journal of International Money and Finance, 31(6):1607-1626.

Chow, G. C. (1960). Tests of Equality Between Sets of Coefficients in Two Linear Regressions. Econometrica, 28(3):591-605.

Chow, K. V. and Denning, K. C. (1993). A Simple Multiple Variance Ratio Test. Journal of Econometrics, 58(3):385-401.

Cochrane, J. H. (1991). A Critique of the Application of Unit Root Tests. Journal of Economics Dynamics and Control, 15(2):275-284.

Cressie, N. A. C. and Whitford, H. J. (1986). How to Use the Two Sample t-test. Biometrical Journal, 28(2):131-148.

Dedunu, H. H. (2017). Weak Form Efficiency of the Sri Lankan Stock Market From 2010-2014. IOSR-Journal of Economics and Finance, 8(3):75-81.

Diba, B. T. and Grossman, H. I. (1988). Explosive Rational Bubbles in Stock Prices. American Economic Review, 78(3):520-530.

Dickey, D. A. and Fuller, W. A. (1981). Likelihood Ratio Statistics for Autoregressive Time Series with a Unit Root. Econometrica, 49(4):1057-1072.

Dragota, V., Ciobanu, A., Cotarama, D., Semenescu, A., and Lacatus, C. (2009). Minority Shareholders' Protection: The Romanian Experience. Theoretical and Applied Economics, $2(2): 35-48$. 
Eakins, S. and Mishkin, F. (2012). Financial Markets and Institutions . Massachusetts.

Elliott, G., Rothenberg, T. S., and Stock, J. H. (1996). Efficient Tests for an Autoregressive Unit Root. Econometrica, 64(4):813-836.

Evans, G. (1991). Pitfalls in Testing for Explosive Bubbles in Asset Prices. American Economic Review, 81(4):922-930.

Fama, E. F. (1965). The Behavior of Stock-Market Prices. The Journal of Business, 38(1):34105.

Gyamfi, E. N. (2018). Adaptive Market Hypothesis: Evidence from the Ghanaian Stock Market. Journal of African Business, 19(2):195-209.

Hall, P. (1992). On the Removal of Skewness by Transformation. Journal of the Royal Statistical Society Series, 54(1):221-228.

Hiremath, G. S. and Narayan, S. (2016). Testing the Adaptive Market Hypothesis and its Determinants for the Indian Stock Market. Financial Research Letters, 19(C):173-180.

Keynes, J. M. (1936). The General Theory of Employment, Interest, and Money. Macmillan.

Kim, J. H., Shamsuddin, A., and Lim, K. P. (2011). Stock Returns Predictability and the Adaptive Market Hypothesis: Evidence from Century-Long U.S. Data. Journal of Empirical Finance, 18(5):868-879.

Kwiatkowski, D., Phillips, P. C., Schmidt, P., and Shin, Y. (1992). Testing the Null Hypothesis of Stationary Against the Alternative of a Unit Root. Journal of Econometrics, $54(1-3): 159-178$.

Lo, A. W. (2004). The Adaptive Markets Hypothesis: Market Efficiency from an Evolutionary Perspective. The Journal of Portfolio Management, 30(5):15-29.

Lo, A. W. (2012). Reading about the Financial Crisis: A Twenty-One-Book Review. Journal of Economic Literature, 50(1):151-178.

Lo, A. W. and Mackinley, C. A. (1988). Stock Market Prices Do Not Follow Random Walks: Evidence from a Simple Specification Test. The Review of Financial Studies, 1(1):41-66.

Morales, R., Matteo, D., T., G. R., and Aste, T. (2012). Dynamical Generalized Hurst Exponent as a Tool to Monitor Unstable Periods in Financial time series. Physica A: Statistical Mechanics and its Applications, 391(11):3180-3189. 
Nagayasu, J. (2003). The Efficiency of the Japanese Equity Market. Working Paper WP/03/142, International Monetary Fund, Washington, D.C.

Neely, C. J., Weller, P. A., and Ulrich, J. M. (2009). The Adaptive Market Hypothesis: Evidence from Foreign Exchange Market. Journal of Financial and Quantitative Analysis, 44(2):467-488.

Ng, S. and Perron, P. (2001). Lag Length Selection and the Construction of Unit Root Tests with Good Size and Power. Econometrica, 69(6):1519-1554.

Oprean, C., Tanasescu, C., and Bucur, A. (2017). A new proposal for efficiency quantification of capital markets in the context of complex nonlinear dynamics and chaos. Economic Research-Ekonomska Istraživanja, 30(1):1669-1692.

Panas, E. and Ninni, V. (2010). The Distribution of London Metal Exchange Prices: A Test of the Fractal Market Hypothesis. European Research Studies Journal, 13(2):192-210.

Perron, P. (1989). The Great Crash,The Oil Price Shock,and the Unit Root Hypothesis. Econometrica, 57(6):1361-1401.

Peters, E. E. (1994). Fractal market analysis. Wiley, New York.

Phillips, P. C. and Perron, P. (1988). Testing for a Unit Root in Time Series Regression. Biometrika, 75(2):335-346.

Phillips, P. C., Shi, S.-P., and Yu, J. (2015). Testing for Multiple Bubbles: Historical Episodes of Exuberance and Collapse in the S\&P 500. International Economic Review, 56(4):10431078.

Phillips, P. C., Wu, Y., and Yu, J. (2011). Explosive Behavior in the 1990s Nasdaq: When Did Exuberance Escalate Asset Values. International Economic Review, 52(1):201-226.

Resta, M. (2012). Hurst Exponent and its Applications in Time-series Analysis. Recent Patents on Computer Science, 5(3):211-219.

Risso, W. A. (2008). The Informational Efficiency and the Financial Crashes. Research in International Business and Finance, 22(3):396-408.

Shaker, A. M. (2013). Testing the Weak-form Efficiency of the Finnish and Swedish Stock Markets. European Journal of Business and Social Sciences, 2(9):176-185.

Shannon, C. E. (1948). A Mathematical Theory of Communication. Bell System Technical Journal, 27(3):379-423. 
Shao, X. and Wu, W. B. (2007). Asymptotic Spectral Theory for Nonlinear Time Series. The Annals of Statistics, 35(4):1773-1801.

Shiller, R. (1979). The Volatility of Long-term Interest Rates and Expectations Models of the Term Structure. Journal of Political Economy, 87(6):1190-1219.

Shleifer, A. (2000). Inefficient Markets: An Introduction to Behavioural Finance. Clarendon Lectures in Economics. OUP Oxford.

Soteriou, A. and Svensson, L. (2017). Testing the Adaptive Market Hypothesis on the OMXS30 Stock Index: 1986-2014 (Master Thesis). Jönköping International Business School, Jönköping.

Todea, A., Ciupac-Ulici, M., and Silaghi, S. (2009). Adaptive Market Hypothesis: Evidence from Asia-Pacific Financial Markets. The Review of Finance and Banking, 1(1):7-13.

Van Quang, T. (2005). The Fractal Market Analysis and its Application on Czech Conditions. Acta Oeconomica Pragensia, 13(1):101-111.

Wald, A. and Wolfowitz, J. (1940). On a Test Whether Two Samples are from the Same Population. Annals of Mathematical Statistics, 11(2):147-162.

Wu, S. (2010). Lag Length Selection in DF-GLS Unit Root Tests. Communications in Statistics-Simulation and Computation, 39(8):1590-1604. 
Figure 1: Time series of daily WIG20 prices

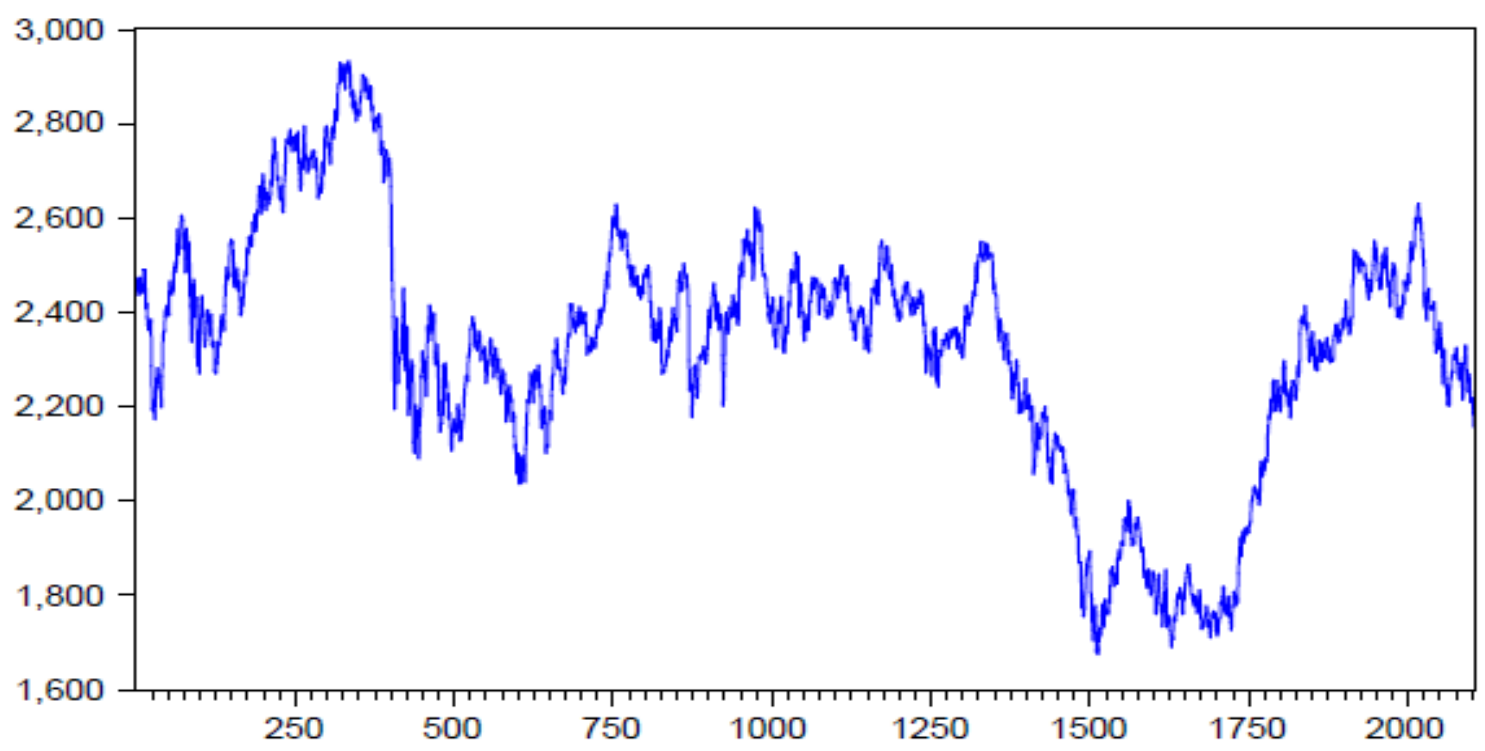

Figure 2: Time series of daily WIG20 returns

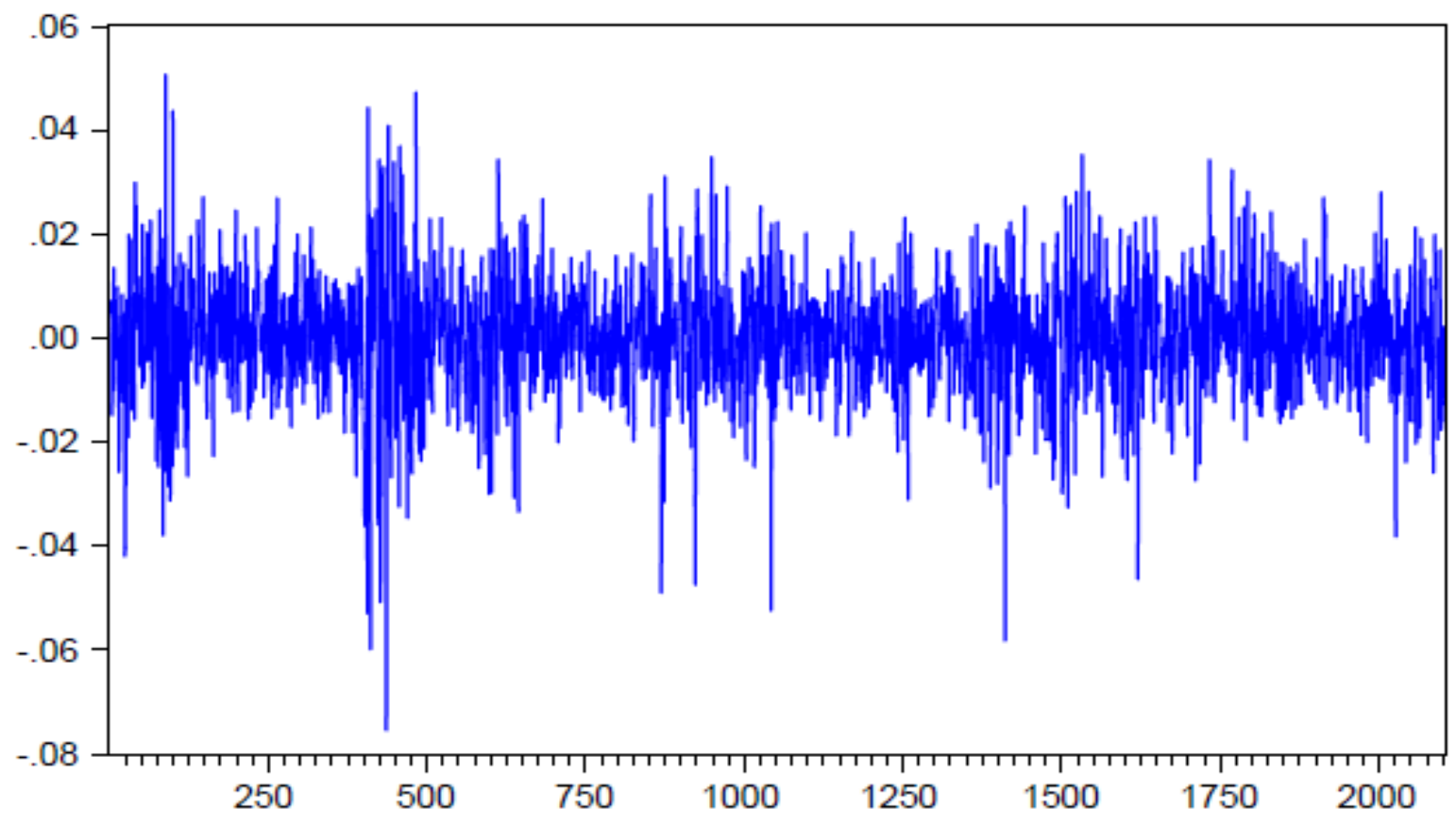


Table 1: Descriptive Statistics

\begin{tabular}{lclc}
\hline Mean & $-4.63 \mathrm{e}-05$ & Standard deviation & 0.011615 \\
Skewness & -0.391367 & Kurtosis & 5.918638 \\
J-B statistic & 798.9732 & J-B probability & 0.00000 \\
\hline
\end{tabular}

Table 2: Results of the Runs Test

\begin{tabular}{cccc}
\hline Test Value & Number of Runs & Z-Statistic & Probability \\
The Mean of Data & 1085 & 1.52 & 0.129 \\
\hline
\end{tabular}

Table 3: Structural Breaks Test

\begin{tabular}{|c|c|c|c|}
\hline $\begin{array}{r}\text { Break ty } \\
\text { vs. L- } \\
\text { Sta } \\
\text { Bre }\end{array}$ & : No Brec & oints Sele & aks \\
\hline $\mathrm{C}$ & $\begin{array}{l}\text { Coefficient } \\
-4.63 \mathrm{E}-05\end{array}$ & $\begin{array}{c}\text { t-statistic } \\
-0.1933\end{array}$ & \\
\hline
\end{tabular}

Note: Break selection is based on trimming 0.15; significance level: 0.05.

Table 4: Unit Root Test Results

\begin{tabular}{cccccc}
\hline & & ADF & P-P & DF-GLS & KPSS \\
\hline Intercept & Statistic & -33.93 & -44.00 & -4.27 & 0.04 \\
& Critical Value & -2.86 & -2.86 & -1.94 & 0.46 \\
\hline Intercept & Statistic & -33.93 & -43.99 & -12.74 & 0.03 \\
and Trend & Critical Value & -3.41 & -3.41 & -2.89 & 0.14 \\
\hline
\end{tabular}

Note: The significant level is $5 \%$. 
Table 5: Variance Ratio Test Results

\begin{tabular}{cccc}
\hline \multicolumn{4}{c}{ Joint Test } \\
\hline Statistic & Value & df & Probability \\
$\operatorname{Max}|Z|($ at Period 2) & 13.68 & 2099 & 0.00 \\
\hline \multicolumn{4}{c}{ Individual Tests } \\
\hline Period & Var. ratio & Z-Statistic & Probability \\
2 & 0.55 & -13.68 & 0.00 \\
4 & 0.26 & -13.03 & 0.00 \\
8 & 0.13 & -10.30 & 0.00 \\
16 & 0.06 & -7.74 & 0.00 \\
\hline
\end{tabular}

Table 6: Shannon's Entropy Index Estimation

\begin{tabular}{lcc}
\hline & 50-Window & 100-Window \\
Mean & 0.9986 & 0.9987 \\
Median & 0.9987 & 0.9988 \\
Max & 0.9999 & 0.9999 \\
Min & 0.9953 & 0.9969 \\
Std. Dev & 0.0008 & 0.0008 \\
Skewness & -1.2230 & -0.4733 \\
Kurtosis & 5.8807 & 2.9108 \\
J-B (Statistic) & 24.9936 & 0.7911 \\
J-B (Prob) & 0.0000 & 0.6732 \\
\hline
\end{tabular}

Note: The significant level is $5 \%$. 
Table 7: $t$-Test Results

\begin{tabular}{lcccc}
\hline & Standard $t$ & $\begin{array}{c}\text { Critical Value } \\
(\alpha=1 \%)\end{array}$ & Trimmed $t$ & $\begin{array}{c}\text { Critical Value } \\
(\alpha=1 \%)\end{array}$ \\
\hline 50-Window & -9.801 & 2.423 & -10.020 & 2.457 \\
& $(41)$ & & $(33)$ & \\
\hline 100-Window & -6.971 & 2.528 & - & - \\
\hline
\end{tabular}

Note: The values in parentheses indicate the degrees of freedom.

Table 8: Hurst Index Estimation

\begin{tabular}{lcc}
\hline & 50-Window & 100-Window \\
\hline Mean & 0.473 & 0.470 \\
Std. Dev & 0.067 & 0.067 \\
Median & 0.463 & 0.465 \\
Max & 0.673 & 0.673 \\
Min & 0.379 & 0.379 \\
Skewness & 1.097 & 1.192 \\
Kurtosis & 4.315 & 4.785 \\
J-B statistic & 11.455 & 7.769 \\
J-B probability & 0.003 & 0.020 \\
\hline
\end{tabular}

Table 9: Trimmed Sample Normality Test

\begin{tabular}{lcc}
\hline & 50-Window & 100-Window \\
\hline J-B (Statistic) & 2.213 & 1.075 \\
J-B (Prob) & 0.330 & 0.584 \\
\hline
\end{tabular}


Table 10: $t$-Test Results

\begin{tabular}{lcccc}
\hline & Standard $t$ & $\begin{array}{c}\text { Critical Value } \\
(\alpha=1 \%)\end{array}$ & Trimmed $t$ & $\begin{array}{c}\text { Critical Value } \\
(\alpha=1 \%)\end{array}$ \\
\hline 50-Window & -2.558 & 2.423 & -3.281 & 2.457 \\
& $(41)$ & & $(33)$ & \\
\hline 100-Window & -2.011 & 2.528 & -2.664 & 2.583 \\
& $(20)$ & & $(16)$ & \\
\hline
\end{tabular}

Note: The values in parentheses indicate the degrees of freedom.

Table 11: Variance Ratio Test Results / Part I

\begin{tabular}{lcccccccc}
\hline Length & Stat & Prob & Length & Stat & Prob & Length & Stat & Prob \\
\hline 50 & 3.24 & 0.00 & 750 & 8.69 & 0.00 & 1450 & 11.18 & 0.00 \\
100 & 3.78 & 0.00 & 800 & 8.95 & 0.00 & 1500 & 11.30 & 0.00 \\
150 & 4.47 & 0.00 & 850 & 9.09 & 0.00 & 1550 & 11.54 & 0.00 \\
200 & 4.95 & 0.00 & 900 & 9.39 & 0.00 & 1600 & 11.74 & 0.00 \\
250 & 5.47 & 0.00 & 950 & 9.49 & 0.00 & 1650 & 12.00 & 0.00 \\
300 & 5.86 & 0.00 & 1000 & 9.85 & 0.00 & 1700 & 12.08 & 0.00 \\
350 & 6.41 & 0.00 & 1050 & 9.79 & 0.00 & 1750 & 12.23 & 0.00 \\
400 & 6.85 & 0.00 & 1100 & 9.93 & 0.00 & 1800 & 12.42 & 0.00 \\
450 & 5.98 & 0.00 & 1150 & 10.03 & 0.00 & 1850 & 12.60 & 0.00 \\
500 & 6.87 & 0.00 & 1200 & 10.17 & 0.00 & 1900 & 12.87 & 0.00 \\
550 & 7.23 & 0.00 & 1250 & 10.32 & 0.00 & 1950 & 13.09 & 0.00 \\
600 & 7.54 & 0.00 & 1300 & 10.42 & 0.00 & 2000 & 13.26 & 0.00 \\
650 & 8.21 & 0.00 & 1350 & 10.56 & 0.00 & 2050 & 13.50 & 0.00 \\
700 & 8.50 & 0.00 & 1400 & 11.03 & 0.00 & 2100 & 13.68 & 0.00 \\
\hline
\end{tabular}

Note: Length indicates window length and Stat indicates variance ratio statistic. 
Table 12: Variance Ratio Test Results / Part II

\begin{tabular}{lcclcc}
\hline Range & Statistic & Prob & Range & Statistic & Prob \\
\hline $1-100$ & 3.78 & 0.00 & $901-1050$ & 3.05 & 0.00 \\
$101-200$ & 4.22 & 0.00 & $1051-1200$ & 4.71 & 0.00 \\
$201-300$ & 3.98 & 0.00 & $1201-1350$ & 3.92 & 0.00 \\
$301-400$ & 4.74 & 0.00 & $1351-1500$ & 4.02 & 0.00 \\
$401-500$ & 3.60 & 0.00 & $1501-1650$ & 4.10 & 0.00 \\
$501-600$ & 4.20 & 0.00 & $1651-1800$ & 4.21 & 0.00 \\
$601-700$ & 4.91 & 0.00 & $1801-1950$ & 5.40 & 0.00 \\
$701-800$ & 4.56 & 0.00 & $1951-2100$ & 4.21 & 0.00 \\
$801-900$ & 2.77 & 0.02 & $1-300$ & 5.86 & 0.00 \\
$901-1000$ & 3.46 & 0.00 & $301-600$ & 5.12 & 0.00 \\
$1001-1100$ & 2.22 & $0.10 *$ & $601-900$ & 6.53 & 0.00 \\
$1101-1200$ & 3.41 & 0.00 & $901-1200$ & 3.96 & 0.00 \\
$1201-1300$ & 3.37 & 0.00 & $1201-1500$ & 5.22 & 0.00 \\
$1301-1400$ & 4.17 & 0.00 & $1501-1800$ & 5.69 & 0.00 \\
$1401-1500$ & 2.86 & 0.01 & $1801-2100$ & 6.60 & 0.00 \\
$1501-1600$ & 3.43 & 0.00 & $1-350$ & 6.41 & 0.00 \\
$1601-1700$ & 2.95 & 0.01 & $351-700$ & 5.94 & 0.00 \\
$1701-1800$ & 3.65 & 0.00 & $701-1050$ & 4.82 & 0.00 \\
$1801-1900$ & 4.37 & 0.00 & $1051-1400$ & 6.56 & 0.00 \\
$1901-2000$ & 4.17 & 0.00 & $1401-1750$ & 5.79 & 0.00 \\
$2001-2100$ & 3.60 & 0.00 & $1751-2100$ & 7.08 & 0.00 \\
$1-150$ & 4.47 & 0.00 & $1-700$ & 8.50 & 0.00 \\
$151-300$ & 4.90 & 0.00 & $701-1400$ & 7.16 & 0.00 \\
$301-450$ & 3.27 & 0.00 & $1401-2100$ & 8.58 & 0.00 \\
$451-600$ & 4.79 & 0.00 & $1-1050$ & 9.79 & 0.00 \\
$601-750$ & 5.57 & 0.00 & $1050-2100$ & 10.59 & 0.00 \\
$751-900$ & 3.71 & 0.00 & & & \\
\hline & & & & &
\end{tabular}

Note: Range indicates the range of data in the interval based on their order in the original returns series. Also, * indicates significance at the $5 \%$ level. 